\title{
People as Infrastructure: Intersecting Fragments in Johannesburg
}

\author{
AbdouMaliq Simone
}

ๆ he inner city of Johannesburg is about as far away as one can get from the popular image of the African village. Though one of Africa's most urbanized settings, it is also seen as a place of ruins — of ruined urbanization, the ruining of Africa by urbanization. But in these ruins, something else besides decay might be happening. This essay explores the possibility that these ruins not only mask but also constitute a highly urbanized social infrastructure. This infrastructure is capable of facilitating the intersection of socialities so that expanded spaces of economic and cultural operation become available to residents of limited means.

This essay is framed around the notion of people as infrastructure, which emphasizes economic collaboration among residents seemingly marginalized from and immiserated by urban life. Infrastructure is commonly understood in physical terms, as reticulated systems of highways, pipes, wires, or cables. These modes of provisioning and articulation are viewed as making the city productive, reproducing it, and positioning its residents, territories, and resources in specific ensembles where the energies of individuals can be most efficiently deployed and accounted for.

By contrast, I wish to extend the notion of infrastructure directly to people's activities in the city. African cities are characterized by incessantly flexible, mobile, and provisional intersections of residents that operate without clearly delineated notions of how the city is to be inhabited and used. These intersections, particularly in the last two decades, have depended on the ability of residents to

Public Culture 16(3): 407-429

Copyright () 2004 by Duke University Press 
engage complex combinations of objects, spaces, persons, and practices. These conjunctions become an infrastructure - a platform providing for and reproducing life in the city. Indeed, as I illustrate through a range of ethnographic materials on inner-city Johannesburg, an experience of regularity capable of anchoring the livelihoods of residents and their transactions with one another is consolidated precisely because the outcomes of residents' reciprocal efforts are radically open, flexible, and provisional. In other words, a specific economy of perception and collaborative practice is constituted through the capacity of individual actors to circulate across and become familiar with a broad range of spatial, residential, economic, and transactional positions. Even when actors do different things with one another in different places, each carries traces of past collaboration and an implicit willingness to interact with one another in ways that draw on multiple social positions. The critical question thus raised in this ethnography of inner-city Johannesburg is how researchers, policymakers, and urban activists can practice ways of seeing and engaging urban spaces that are characterized simultaneously by regularity and provisionality.

Urbanization conventionally denotes a thickening of fields, an assemblage of increasingly heterogeneous elements into more complicated collectives. The accelerated, extended, and intensified intersections of bodies, landscapes, objects, and technologies defer calcification of institutional ensembles or fixed territories of belonging. But does this mean that an experience of regularity and of sustained collaboration among heterogeneous actors is foreclosed? We have largely been led to believe that this is the case. Thus, various instantiations of governmentality have attempted to emplace urbanizing processes through the administration of choices and the codification of multiplicity. The potential thickness of social fields becomes the thickness of definitions and classifications engineered by various administrations of legibility and centers of decision making. ${ }^{1}$ Once visible, the differentiated elements of society are to assume their own places and trajectories and become the vectors through which social power is enunciated.

In this view, urban spaces are imagined to be functional destinations. There are to be few surprises, few chances for unregulated encounters, as the city is turned into an object like a language. ${ }^{2}$ Here, relations of correspondence are set up between instances of two distinct and nonparallel modes of formalization - of

1. Henri Lefebvre, The Production of Space (Oxford: Blackwell, 1991).

2. Henri Lefebvre, Writings on Cities, trans. Eleonore Kofman and Elizabeth Lebas (Cambridge, Mass.: Blackwell, 1996). 
expression and content. ${ }^{3}$ Particular spaces are linked to specific identities, functions, lifestyles, and properties so that the spaces of the city become legible for specific people at given places and times. These diagrams - what Henri Lefebvre calls "representations of space"-act to "pin down" inseparable connections between places, people, actions, and things. ${ }^{4}$ At the same time, these diagrams make possible a "relation of non-relation" that opens each constituent element onto a multiplicity of relations between forces. ${ }^{5}$ In this multiplicity of connotations, it is always possible to do something different in and with the city than is specified by these domains of power while, at the same time, acting as if one remains operative inevitably only within them. ${ }^{6}$ This notion of tactics operating at the interstices of strategic constraints is a recurring theme in the work of Michel de Certeau. ${ }^{7}$

In other words, the disposition of regularities and the outcomes of collaborative work in the city can be open ended, unpredictable, and made singular. The truncated process of economic modernization at work in African cities has never fully consolidated apparatuses of definition capable of enforcing specific and consistent territorial organizations of the city. State administrations and civil institutions have lacked the political and economic power to assign the diversity of activities taking place within the city (buying, selling, residing, etc.) to bounded spaces of deployment, codes of articulation, or the purview of designated actors. According to conventional imaginaries of urbanization, which locate urban productivity in the social division of labor and the consolidation of individuation, African cities are incomplete. ${ }^{8}$ In contrast to these imaginaries, African cities survive largely through a conjunction of heterogeneous activities brought to bear on and elaborated through flexibly configured landscapes. But it is important to

3. Cary Wolfe, Critical Environments: Postmodern Theory and the Pragmatics of the Outside (Minneapolis: University of Minnesota Press, 1998).

4. Henri Lefebvre, "Reflections on the Politics of Space," trans. Michael Enders, Antipode 8 (1976): 33 .

5. Lefebvre, "Reflections," 33; Gunnar Olsson, "From a = b to a = a," Environment and Planning A 32, no. 7 (2000): 1242.

6. John Rajchman, Constructions (Cambridge, Mass.: MIT Press, 1998).

7. Michel de Certeau, The Practice of Everyday Life (Berkeley: University of California Press, 1984).

8. This is a common assumption about the nature of urban Africa but one with its own histories and disputes. See David M. Anderson and Richard Rathbone, "Urban Africa: Histories in the Making," in Africa's Urban Past, ed. David M. Anderson and Richard Rathbone (Oxford: James Currey, 2000). 
emphasize that these flexible configurations are pursued not in some essential contrast to non-African urban priorities or values but as specific routes to a kind of stability and regularity that non-African cities have historically attempted to realize. Consider the incomplete, truncated, or deteriorated forms and temporalities of various, seemingly incompatible institutional rationalities and modes of production - from the bureaucracies of civil administration to the workshop, the industrial unit, subsistence agriculture, private enterprise, and customary usufruct arrangements governing land use. All are deployed as a means of stabilizing a social field of interaction. In part, this is a way to continuously readapt residents' actions to engage the open-ended destinations that their very collaborations have produced.

For example, the transport depot in Abidjan is full of hundreds of young men who function as steerers, baggage loaders, ticket salespersons, hawkers, drivers, petrol pumpers, and mechanics. There are constantly shifting connections among them. Each boy who steers passengers to a particular company makes a rapid assessment of their wealth, personal characteristics, and the reason for their journey. This reading determines where the steerer will guide prospective passengers, who will sell their tickets, who will load their baggage, who will seat them, and so forth. It is as if this collaboration were assembled to maximize the efficiency of each passage, even though there are no explicit rules or formal means of payment to the steerers. Although each boy gives up control of the passenger to the next player down the line, their collaboration is based not on the boys adhering to specific rules but on their capacity to improvise.

Such a conjunction of heterogeneous activities, modes of production, and institutional forms constitutes highly mobile and provisional possibilities for how people live and make things, how they use the urban environment and collaborate with one another. The specific operations and scopes of these conjunctions are constantly negotiated and depend on the particular histories, understandings, networks, styles, and inclinations of the actors involved. Highly specialized needs arise, requiring the application of specialized skills and sensitivities that can adapt to the unpredictable range of scenarios these needs bring to life. Regularities thus ensue from a process of incessant convertibility - turning commodities, found objects, resources, and bodies into uses previously unimaginable or constrained. Producer-residents become more adept at operating within these conjunctions as they deploy a greater diversity of abilities and efforts. Again it is important to emphasize that these conjunctions become a coherent platform for social transaction and livelihood. This process of conjunction, which is capable of generating social compositions across a range of singular capacities and needs 
(both enacted and virtual) and which attempts to derive maximal outcomes from a minimal set of elements, is what I call people as infrastructure. ${ }^{9}$

This concept is not meant to account for inner-city Johannesburg in its entirety. Many residents, battered by the demands of maintaining the semblance of a safe domestic environment, find few incentives to exceed the bounds of personal survival. But people as infrastructure describes a tentative and often precarious process of remaking the inner city, especially now that the policies and economies that once moored it to the surrounding city have mostly worn away. In many respects, the inner city has been "let go" and forced to reweave its connections with the larger world by making the most of its limited means. Still, the inner city is embedded in a larger urban region characterized by relative economic strength, an emerging pan-African service economy, political transformations that have sought to attenuate the more stringent trappings of population control, and a highly fragmented urban system whose regulatory regime was never geared toward highdensity residential areas. This ensemble, in turn, has given rise to a markedly heterogeneous domain of people.

\section{Spaces of the Inner City}

Under apartheid, Johannesburg was designed as a cosmopolitan, European city in Africa, but only for a small segment of its population. When this truncated cosmopolitanism could no longer be enforced by a white minority regime, whites fled to distant northern suburbs and gated communities where cosmopolitanism was precluded, thus leaving the inner city open to habitation of all kinds. Roughly 90 percent of Johannesburg's inner-city residents were not living there ten years ago.

A drive around the circumference of the inner-city neighborhoods of Hillbrow, Berea, Joubert Park, Yeoville, and Bertams takes less than twenty minutes. Yet navigation of their interior requires familiarity with many different and, on the surface, conflicting temporal trajectories through which Johannesburg has changed, with its sudden switches across ruin, repair, and redevelopment. For example, a

9. This notion attempts to extend what Lefebvre meant by social space as a practice of worksmodes of organization at various and interlocking scales that link expressions, attraction and repulsion, sympathies and antipathies, changes and amalgamations that affect urban residents and their social interactions. Ways of doing and representing things become increasingly "conversant" with one another. They participate in a diversifying series of reciprocal exchanges, so that positions and identities are not fixed or even, at most times, determinable. These "urbanized" relations reflect neither the dominance of a narrative or linguistic structure nor a chaotic, primordial mix. 
five-minute walk along Quartz Street starting at Smit Street takes you from Death Valley, a strip of seedy prostitution hotels and clubs, to a concerted effort to resecure the tenancy of working families in a series of tightly controlled renovated buildings. In part, this minor effort at gentrification was motivated by a sense that the block north of Smit Street had become way too dangerous. From the late 1980s through the late 1990s, Death Valley functioned as "sex central"with scores of bored prostitutes waiting at all times of day in the alcoves of its hotels.

There was little safety in numbers for participants in this sex market; the concentrated availability of bodies served only to increase the exploitation of prostitutes. As a result, whatever and whoever passed through this particular area of Smit Street acquired a large measure of expendability. The immediate area emptied out yet remains a kind of no-go zone, with the traces of the wild recent past still keeping other prospects at bay. Still, just one block away is the New Yorker, a relatively well-appointed block of studio apartments recently fixed up and with a long waiting list restricted to South Africans who can show five pay stubs.

Further north there is a single block along Quartz Street where hundreds of Ibo Nigerians gather on the street, usually between 2 and 7 p.m. They are here not so much to deal narcotics, for which they are renowned, but to display impunity and solidarity while buying daily meals from the curbside street vendors. It is, of course, always possible to buy a packet of drugs or arrange a larger quantity. The King's Den, a bar whose second-story veranda overlooks the street, usually hosts the more prominent "middlemen," whose drivers pull up in red and black Jettas. Many of these men, now in their mid-fifties, retain the Ibo dress of boubous (robes) and felt skullcaps, as well as a sense of determination honed in the labor movements of Port Harcourt and Calabar, Nigeria. The block used to serve as a taxi stand for Lingala-speaking drivers waiting for calls from the airport, and a few still remain to ferry the occasional Greek, Zambian, or Congolese desperate to unload marginal contraband from Lubumbashi, Democratic Republic of Congo, so they can shop in the wealthy suburb of Sandton.

Several young Ibo men have told me that part of the reason for this public display is to reaffirm the fact that they are in Johannesburg in large numbers. But this affirmation of common nationality does not translate into ready collaboration. They cannot forget that despite whatever skills they may have-whether formal postgraduate education, vast knowledge about trade, or street smartsthere are likely to be scores of their compatriots who are more proficient in these areas. Thus, there is an incessant need to do something bold yet not rash. The older men, the ones with the real money or connections, watch to see what vari- 
ous individuals are capable of doing. And so the younger ones submit to being watched. A few bide their time selling cigarettes and candy; almost all engage in shifting conversations. Many wait to take their turn at the Internet cafe just around the corner (where one can buy five hours of computer time and get the sixth free) to engage in credit card fraud, check shipping orders, or write e-mails to mom or 419 letters. ${ }^{10}$

Crossing Kotze Street, Quartz Street is interrupted by the somewhat frayed Highpoint Centre - a large apartment block anchored by a supermarket and other commercial properties, many of them now abandoned. Because it is watched by security guards, the mezzanine is a popular place to withdraw money from ATMs. There is also a beauty parlor and another Internet cafe; but the porterhouse steak restaurant, the recreational center, the American Express travel agency, and the health food store have long been closed. A Zambian company now manages the complex and is fairly well regarded by local residents and customers because it maintains an office on the premises and has kept the local stationary and magazine store open (where the strong educational desires of children and youths translate into purchases of vast quantities of pens and notebooks). Five years ago, the residential part of this complex — some three hundred flats — used to be the turf of Coloured people, now all gone. Underneath Highpoint Center is a cavernous parking garage. The last time I ventured there, by mistake at two in the morning some two years ago, I found hundreds of women, adherents of the Zionist Christian Church, kneeling in unison.

On the other side of Pretoria Street is a block representing an early effort by the Metropolitan Council to draw street traders into an organized market with rented stalls and shedding. A variety of fruits and vegetables are sold here, as well as clothing, shoes, and kitchen goods. But the traders must pay rent for their stalls. Although the money is used to provide a clean and safe environment, its goods are consequently more expensive than those of the hawkers who still line much of Pretoria Street and whose trade this formal market was supposed to dispel. As we continue north along Quartz Street, the formal market dissipates in a contiguous block of unregulated street hawkers and alleys where stolen goods are sold. But in the surrounding arteries there are large apartment blocks, and it is

10. 419 refers to a type of scheme in which mass mailings are sent out, seemingly from a prominent, usually Nigerian, figure or company that needs to get large amounts of money out of the country. In return for temporary use of the recipient's bank account or other financial instruments, a significant share of these funds is promised. The letter usually requests a faxed authorization to deposit these funds, which in turn enables the 419 fraudster to withdraw money from the account. Often, 419 victims are enticed to come to Nigeria, where they are robbed or extorted. 
clearly an area where the South African township has moved in. The pool halls and game rooms are crowded, and the block pulses with hip-hop and kwaito music. Corner walls are lined with hundreds of makeshift notices offering rooms for rent. Every ten yards, it seems, there is a shop or improvised street stand with a telephone - an important service for the majority of residents who cannot afford their own phones. Ten years ago there were German pastry shops, health clubs, and tie shops on this block. On the many occasions when I have crossed this stretch between Goldreich and Caroline streets, I have always seen violent incidents: a single shot to the head, or even an assengai, a short spear, quickly thrust and removed. Crowds gather, mostly in silence, as calls are made to police officers who are in sight just a few blocks away, stopping cars in the cocaine zone.

The next block is inhabited by homeless squatters, whose cardboard edifices and stolen shopping carts line mounds of burnt ash from fires they use to cook and keep warm. There is an acrid smell and the incessant sounds of whistles and catcalls. Young street toughs, Congolese mechanics who use a nearby petrol station to repair and store cars, and Malawians who have long dominated the residential buildings all engage in a territorial dance for control of the block.

Finally the street ends at a major lateral artery, Louis Botha Avenue, and the Mimosa Hotel. The Mimosa is one of about ten hotels operated, if not owned, by Nigerian syndicates, where rooms are shared to keep accommodations for an army of "foot soldiers" under R10 (roughly \$1.50) per night. Here, recent doctorates in designer frames mingle across street-side card tables with ex-Area boys from Lagos on the run from being framed. Some keep an eye out for everything. Others wait to unload the small quota of narcotics that will allow them to eat that night. There are those who direct old and new clients to choice rooms in the hotel in order to meet their needs; and still others are there to tell stories, often about deals both real and made up. These are imported tricksters, whose job is to celebrate the ruthless economy that most of these young Ibo guys pursue, provide occasional cautionary tales, but in the end get others to reveal what they are after, what their capacities are, where they have been, and how well they might fit certain jobs. The police and the city council have declared victory over Nigerians several times by shutting down the hotel. On the ground level, a passing observer might be fooled into thinking that the place is finished, but if you look up you might notice that the windows are full of freshly laundered clothes. 
This is an inner city whose density and highly circumscribed spatial parameters compel uncertain interactions and cooperation among both long-term Johannesburg residents and new arrivals, South Africans and Africans from elsewhere. There are interactions among various national and ethnic groups, between aspiring professionals and seasoned criminals, and between AIDS orphans living on the streets and wealthy Senegalese merchants living in luxurious penthouses. At the same time, life in the inner city fosters intense cooperation among fellow nationals and ethnics. The coupling of these trajectories produces an intricate territorialization and a patchwork of zones of relative security. Some blocks and many buildings clearly "belong" to particular national groups, in part due to the disparate practices employed by building owners and their managing agents. These actors have their own interpretations of the relative benefits and costs of renting to South Africans or foreigners.

To what extent does this narrowing of space along ethnic or national lines enforce a ghettoization of economy or mentality? For those who are rigidly ensconced in a limited territory of relative safety and predictability, everyday familial and public relations can be quite strained, even suffocating. ${ }^{11}$ However, such circumscribed spatial arenas are only one domain within a networked milieu of diverse locations through which residents pass, and which are actively or symbolically linked to the seemingly highly bounded inner-city territories. For many South Africans, these inner-city neighborhoods are linked to long-standing townships or periurban settlements. Hillbrow, for example, has often served as a place of both temporary and long-term escape from problematic kinship and neighborhood relations in Soweto. For those living in the vast squatter areas of Orange Farm, south of the city, Joubert Park serves as an anchor for small-scale trading across Johannesburg. Zimbabweans and Malawian sojourners and petty traders, coming back and forth often on two-week visas, use several large inner-city hotels as temporary bases of operation and storage. For many Africans across the region, Johannesburg is a site for the bulk purchase of various commodities. It is a locus of complex barter arrangements and transshipment, a site for laundering money, sending remittance, and for upscaling a variety of entrepreneurial activities through the dense intersections of actors from different countries and situations.

11. Alan Morris, "Race Relations and Racism in a Racially Diverse Inner City Neighbourhood: A Case Study of Hillbrow, Johannesburg," Journal of Southern African Studies 25, no. 4 (1999): 667-94. 
But a "cat and mouse" game largely prevails. Many foreign Africans cite the need for maintaining hyperawareness of their surroundings. They are constantly on the lookout for police officers, many of whom seem focused on entrapping foreigners in various shakedowns, luring them into what appear to be highly favorable apartment rentals only to then raid them and expropriate money and goods. When interviewing migrants, one notices their constant wariness about whom they can safely talk to and in what contexts. There are multiple levels of intrigue and conflict among migrants from the same region, regardless of whether they share common ancestry, politics, or commercial experience. Such infighting is typical among South African institutional personnel as well. For example, a wellknown story concerns a police raid on a Senegalese mosque in Bez Valley during Ramadan, when the large Murid Senegalese community in Johannesburg was gathering contributions to be sent to the religious center of Touba, Senegal. Apparently, a Gambian immigrant dealing in false papers had targeted a Senegalese rival, whom the police threatened to toss from the window of his nineteenthstory apartment in Hillbrow unless he was able to "do something for himself" (i.e., come up with a large payoff) within twenty-four hours.

Despite this incident, the Senegalese community is much admired in Johannesburg for its ability to work together in highly complementary ways across geographical distance and commercial sectors. The political vicissitudes of almost all other African "feeder" nations generate a great deal of suspicion and internal conflict within national communities residing in Johannesburg, especially as political events constantly send new groups of varying political complexions into exile. With a few exceptions, common national identity provides only a limited platform for economic and social collaboration. The fact that the Senegalese are able to draw on such collaboration provides an important point of reference. Efforts are made to reconstitute such an experience across national identities, particularly where subgroupings of individuals sharing a common national identity are framed within a larger rubric of regional, religious, or professional commonality.

For example, common national identity can provide a concrete framework for support among individuals who may have very different kinds of jobs, ranging from repairing automobiles to teaching French at the Alliance Française. These articulations are used by larger corporate groupings - cutting across several national identities - that facilitate various business efforts through subcontracting arrangements. One such enterprise might draw on the professional legitimacy of teachers, use their students as potential customers or corporate informants, and incorporate the trading circuits developed by petty traders and the repair skills of mechanics. 
The game can take on a simultaneously sinister and comical quality. Bakassi Boys chase after former Revolutionary United Front sobels to settle ECOWAS scores; they are aided by Gambian ex-soldiers who refused to support the Casamance rebel-backed marijuana trade that sustained Yaya Jammeh's government. Zanu-PF veterans of the liberation war rob the suburban houses of Rally for Congolese Democracy-aligned businessmen, who in turn use money earned by Lissouba-backed Zulu militias from Brazzaville to make another run at Sassou Nguesso's Cobras. ${ }^{12}$ The inner city boasts an array of ex-combatants, intelligence operatives, and exiled politicians all chasing one another, all running from one another, and in the process many strange bedfellows and business ventures emerge. At one time, the majority of these actors may have represented a cause, an ethnic group, or a nation. But these identities get lost in Johannesburg, and their new affiliations can be traced only by following how they move from one opaque deal to the next.

The relative absence of a systematic and formal framework for investment in the inner city means that the ideas, entrepreneurial experience, and networks that the bulk of foreign Africans bring to Johannesburg are largely underutilized. A prevailing xenophobia among many South Africans forces Africans from other countries to regulate their visibility - their dress, residential location, and the kinds of economic activities they pursue. As a result, many foreign actors have focused on taking quick profits and marshalling critical sections of the built environment to support the trade in narcotics, stolen goods, and various Internetbased fraud schemes like the infamous $419 \mathrm{~s}$ and credit card scams. According to my interviews with various foot soldiers and middlemen in these loosely organized, largely Ibo-based syndicates, the profits from this trade are used to import a broad range of commodities, such as industrial parts, consumer goods, electronics, and machinery, from Southeast Asia to West and Central Africa.

12. Bakassi Boys is a network of well-organized youth gangs that controls many neighborhoods in southern Nigerian cities and increasingly has operated as a paramilitary force for various politicians. Sobels were military personnel in the Sierra Leone Army who, in the late 1990s, joined with the opposition rebel movement, the Revolutionary United Front, to try to control the diamond trade. Yaya Jammeh is the president of Gambia; originating from a town reputed to be at the center of the regional marijuana trade, Jammeh assumed power as a young soldier in his late twenties. Zanu-PF is the ruling party of Zimbabwe, whose military assumed control of many mineral concessions in the Democratic Republic of Congo when Laurent Kabila, the former head of state, requested Zimbabwe's assistance in the long civil war (in which the Rally for Congolese Democracy is one of the primary antagonists). South Africa has hosted a protracted series of negotiations among the main armed groups to try to bring an end to the conflict. Pascal Lissouba is the former head of state of the Republic of Congo; he was replaced by Daniel Sassou-Ngueso. Both men organized private militias during their struggle for power, which largely decimated the capital city of Brazzaville during the mid-1990s. 
Inattention to the realities of the inner city by key municipal and corporate institutions has led to an intensification of the xenophobic attitudes that force foreign Africans deeper underground. Residents' efforts to secure the range of illicit and informal trades available to them by consolidating control over specific spaces, clients, and domains of inner-city life increasingly clash with the limited upgrading and redevelopment initiatives pursued by the key municipal institutions, such as the Johannesburg Development Agency, the Better Buildings Program, and the Central Johannesburg Partnership. Normative interventions center on major building projects, such as the new Constitutional Court building just west of Hillbrow with its anticipated multiplier effects of increased property values and the restoration of commercial zones. They also entail the demolition of residential buildings with substantial arrears and code violations, the use of existing bylaws to clear out buildings and hotels used for illicit activities, and the seizure of illegally acquired assets. ${ }^{13}$ The complicity of some police officers and customs and immigration officials, as well as the enormous costs of continuous and targeted regulation, limit the efficacy of these interventions.

While residents of different backgrounds try to keep out of one another's way, they do form emergent interdependencies ranging from crude patron-client relations to formally constituted pan-African entrepreneurial collaborations. The sheer proximity of Africans from diverse ethnic and national backgrounds leads many residents to explore tentative cooperation based on trust. Such relationships are risky in a climate of insecurity and incessant trickery, but also enable participants to exploit, in highly profitable ways, the common assumption that trust is not really possible. Given the various skills and networks that different immigrant groups bring to the table, the potential profits in combining trades, markets, and networks far exceed those from commercial activities compartmentalized within narrow ethnic and national groupings. Examples include the buying, selling, and repairing of cars or the domestic or international consigning of goods by individual traders using informal credit systems and flexible collateral. Other activities, usually managed by women, include the cultivation of informal restaurants and bars as safehouses for potentially volatile negotiations among those conducting illegal business. Young women of various nationalities are increasingly enrolled and partnered as foot soldiers in barter schemes - for example, gems for luxury accessories - that may take place in Brazil or Venezuela.

It is difficult to infer the existence of a collective system from even scores of

13. Based on a series of interviews conducted by Bascom Guffin with staff of the Johannesburg Development Agency and the Central Johannesburg Partnership, July 8-10, 2002. 
individual interviews or multisite field observations. Yet it may be possible that this texture of highly fragmented social space and these emerging interdependencies complement each other in forming an infrastructure for innovative economic transactions in the inner city.

\section{Operating Infrastructures}

Such infrastructure remains largely invisible unless we reconceptualize the notion of belonging in terms other than those of a logic of group or territorial representation. People as infrastructure indicates residents' needs to generate concrete acts and contexts of social collaboration inscribed with multiple identities rather than in overseeing and enforcing modulated transactions among discrete population groups. For example, no matter how much Nigerians and South Africans express their mutual hatred, this does not really stop them from doing business with each other, sharing residences, or engaging in other interpersonal relations. The dissipation of once-relied-upon modes of solidarity, the uprooting of individuals from familiar domains, and the ghettoization of individuals within highly circumscribed identity-enclaves constitute an explosive mix of amorphous urban conflict. Residents can orient themselves in this conflict and discover profitable opportunities only through constant interactions with real and potential antagonists.

Efforts on the part of both the urban government and civil society to reconstitute viable territories of belonging and accountability through an array of decentralization and popular participation measures may have the converse effect of highlighting the failures of groups and individuals to secure themselves within any durable context. A coalition of churches, community arts programs, environmentalist NGOs, and community policy projects has attempted to transform small inner-city blocks in Joubert Park into outdoor public gathering places where local artists and theater groups can perform or display their work. Local craft markets, beautification projects, youth workshops, peace festivals, "take back the street" campaigns, and citizen ward committees have all been initiated to facilitate a sense of community and local solidarity. But this is a "community" where the negotiations, ownership, and financial responsibilities involved in maintaining a stake in an apartment are complexly layered. This is a community where the insecurity of residence and the dangers of movement generate a home-grown industry in various forms of protection and payoffs and where a certain stability to public spaces and streets is fostered by the sense that anything could happen to anyone, that no one has an advantage over everyone else. As such, community 
building is often perceived by residents as a peripheral disciplinary exercise that distracts residents from developing the real skills that they need to survive. Community building projects tend to micromanage a wide range of day-to-day political and economic relationships in order to promote public safety and enterprise. But this approach is ineffective, for the inner city requires not only opportunism but precisely the ability to hide one's intentions and abilities within complex relationships of mutual dependence.

The Metropolitan Council of Johannesburg has established ward committees to try to make politics responsive to local needs and styles. But as governance is relocated to the particularities of discrete places, the responsibility of citizens to embody and display normative attitudes toward managing their individual performances as entrepreneurial agents is also entrenched. Urban politics then operates not as a locus of mediation and dialogue among differing experiences, claims, and perspectives but as a proliferation of technical standards by which every citizen's capacities are to be compared and judged. In such a politics, everyone is found wanting, and group identity is reaffirmed as both compensation for and insulation from expanding fields of interaction whose implicit objective is to reproduce the compartmentalization of individuals.

The narcotics enterprises that constitute an important component of the innercity economy are commonly seen as the purview of Ibo-dominated Nigerian networks. While this may generally be true, narcotics enterprises are by no means ethnically or nationally homogeneous. Rather, in a business that has little recourse to legal or official commercial standards, the appearance of ethnic or national homogeneity is used to convey a certain impenetrability. It deflects external scrutiny, infiltration, and competition and thus allows the enterprise to covertly incorporate the diversity of actors it often requires in order to constantly change supply routes, markets, and so forth. In other words, such enterprises parody a national or ethnic notion of belonging.

In the commercial culture of the inner-city narcotics economy, the discrete tasks of importation, circumvention of customs regulations, repackaging, local distribution, money laundering, dealing with legal authorities, territorial control, market expansion, and plotting traffic routes are complementary yet highly territorialized. Usually, discrete units administer each domain so that disruptions in one do not jeopardize the trade. Nigerian syndicates have instituted an interesting governance structure, which uses the hotels in Hillbrow to accommodate a large transient population that camouflages their development of a steady clientele of drug users, including sex workers. The hotels, now largely managed by Nigerian syndicates, become discrete localities housing not only workers in the drug trade 
but also Nigerians working in a wide range of activities. These syndicates are largely hybrid organizations incorporating elements of preexisting Nigerian organizations into evolving organizations specific to the Nigerian experience in Johannesburg. They dominate the governing committees that establish rules for each hotel. For example, there are often no-go areas for Nigerians; and fines, used for legal fees incurred by residents in criminal cases, are levied for various infractions, such as storing stolen goods in the building. Nigerians not directly involved in the drug economy are also counted on to provide a semblance of internal diversity, even if they are often used and manipulated for their access to cars, office machinery, or social connections. The individual operations of the drug trade must be integrated in such a way that complicity and cooperation become the prevailing practices. Within each domain, each operator has a specific place and is expected to demonstrate unquestioning loyalty. This is the case even though the illicit nature and practical realities of the trade constantly generate opportunities for participants to seek greater profits and authority outside the syndicate hierarchies.

Thus, it is apparent to most inner-city residents which hotels, residential buildings, and commercial enterprises belong to which syndicates and what their national affiliations are. Since any given narcotics enterprise handles only certain facets of the overall drug trade - and renders itself vulnerable if it attempts to dominate more functions or territory - neutral spaces must also be defined and maintained. But it is precisely within these spaces, where anything might happen, that the most vociferous claims of belonging emerge. These are often articulated through "contests" over women motivated by the impression (common among South African men) that economically better-off migrants are stealing local women.

Thus, the inner city has a complex geography that residents must navigate according to a finely tuned series of movements and assumptions. There are places where they know they must not go or be seen - but this knowledge often depends on highly variable notions about which places are safe and which are not. A South African municipal worker living in the well-run Metropolitan apartment blocks in Berea is unlikely to sit and read the newspaper in the lobbies of the Mark or Sands hotels, domains of Nigerian drug dealers. But even though this municipal worker would have to make his or her way along a street packed with thousands of drug dealers from noon until midnight, this would actually be safer than making a telephone call from the public stand at the nearby petrol station.

The drug economy, with its hyperactive sensibilities and codes of belonging, has been able to entrench itself in Hillbrow and Berea precisely because these 
dense, highly urbanized areas were being vacated both by their former residents and by financial and governmental resources. The drug operations tend to provincialize certain parts of the inner city in relation to clearly marked territories and fiefdoms. But the boundedness of organizations and territories is more a necessary performance than a description of actual operations. The more entrenched and expansive the drug economy becomes, the more it is compelled to generate ambiguous interfaces. These include interfaces between supposedly discrete groups, between illicit activity and legitimate investment, and between inner-city Johannesburg as an increasingly well-known site of the drug economy and other less visible, and often more advantageous, sites of operation.

Here the salience of belonging specifies the need for its own demise. A frequently heard rallying cry in the inner city is for blocks and neighborhoods to be restored to their "real" owners - but who are these citizens and what would they do with these neighborhoods? To what extent is the drug economy the most visible component of an otherwise invisible unfolding of the inner city onto the uncertainties of the metropolitan region? In a city preoccupied with questions of belonging, where movements and operations are insecure, there is a heightened need to identify spaces of safe residence. Yet the drug operations do not need the inner city either as market or base of operation. Already there is some indication that several syndicates are moving on, seeking other locales, and that associations over the past decade between specific agents and specific territories have become more arbitrary. One can even hear local nostalgia for this territorialization in claims that drug dealers stalled the demise of certain blocks, which are now vulnerable to an influx of petty criminals.

While immigrant networks depend on the constant activation of a sense of mutual cooperation and interdependency, these ties are often more apparent than real - especially as a complex mixture of dependence and autonomy is at work in relations among compatriots. For many foreign Africans in the inner city, Johannesburg is neither the preferred nor the final destination, especially at present. Because the South African economy is increasingly intertwined with other African national and regional economies, Johannesburg is more accessible to foreign migration than are European or North American destinations. The city's geographic location facilitates the petty- to medium-scale (whether conventional or unconventional) trade that characterizes a significant percentage of immigrant economies. In the official commercial and informal markets of Congo-Brazzaville, Congo-Kinshasa, Zambia, Angola, or Mozambique, a substantial percentage of commodities originates in or is imported through South Africa, often by South African-based immigrants. 
Although most immigrants dream of a quick score that would enable them to return home with significantly enhanced prestige and purchasing power, this rarely happens. Instead, the norm is many years of toil in a series of low-wage jobs, with the bulk of one's savings remitted back home to support an array of family members. Additionally, there are often bribes to pay to policemen and unofficial surcharges owed to landlords. All traders run the risk of goods being seized, lost, or stolen. The perseverance of immigrants - especially in South Africaonly highlights the enormousness of the difficulties they would face at home. While fellow nationals or immigrants of various nationalities may band together to share living expenses, information, and risk, the possibilities for corporate action are limited. Individuals try their best to make ends meet and to deal with specific family, community, or political situations back home. Each is in some way a competitor, and cooperation is based on self-interest, self-protection, and camaraderie, not on a long-term investment in the cultivation of a place of operation in Johannesburg.

These dynamics take place in an urban environment that, however fleetingly, once hinted at the possibility of a more cosmopolitan urban South Africa. But the country has long repressed what the image of that cosmopolitanism might look like. Instead, it is reimagined primarily in politically vacuous, "rainbow nation" terms. The inner city has existed for what feels like a lifetime without any significant development of urban policy or programming-especially during the period between 1988 and 1994, when the residential controls of apartheid were suspended and a rapid demographic shift took place.

The inner city largely represents a process of running away, where the inside and the outside render ambiguous any definite sense of where residents are located and what their identities and interests really are. Black South Africans are fleeing the restrictive sociality of township life, a life too long situated in arbitrary, isolated places designed to prevent cultural reproduction. Foreign Africans, fleeing sometimes deadly conflicts in their native countries, are seeking whatever is possible to maintain a sense (and often just the illusion) of home. Still, an extensive transactional economy has developed from the range of tactics that residents use to deflect constraint, surveillance, and competition and from the varied forms of sociality that emerge to increase access to information, destinations, and support. It is to these transnational economies that the inner city increasingly belongs. 


\section{Infracity: Johannesburg and Urban Africa}

On the surface, inner-city Johannesburg has many features in common with inner cities in the United States. Many of the economic and political mechanisms that produced American inner-city ghettos have been at work in Johannesburg, and these are only reinforced by the strong influence of U.S. urban policy on South Africa. But large swathes of Johannesburg reflect the failures of strong regulatory systems and the economic and social informalities commonly associated with urban Africa. To this extent, inner-city Johannesburg is a kind of hybrid: part American, part African. Indeed, it is mainly Johannesburg's American features its developed physical infrastructure, social anonymity, and extensive range of material and service consumption - that have attracted large numbers of urban Africans. It is easy to show that changes in the global economy have substantially restructured and respatialized cities everywhere, often around residual pockets of ruin. The potential significance of reflections on Johannesburg, in contrast to other global cities, rests in how the city embodies, speeds up, and sometimes brutalizes aspects of urban life common to many African cities.

One such aspect is its urban residents' constant state of preparedness. Driven by discourses of war, contestation, and experimentation, many African cities seem to force their inhabitants to constantly change gears, focus, and location. Of course, there are some quarters whose residents have grown up, raised families, and devoted themselves to the same occupation or way of life without moving. Yet even this stability is situated within a larger, more fluid arena where people must be prepared to exert themselves. There is the need to ensure oneself against a lifetime without work or the means to establish a family or household of one's own. There is the need to prepare for the possibility that even hard work will produce nothing.

There is the need to prepare for an endless process of trickery. Government officials trick citizens with countless pronouncements of progress while finding new and improved ways of shaking them down. Parents trick their children with promises of constant nurturing - if only they would sell themselves here or there, as maids, touts, whores, or guardians. And children trick their parents with promises of support into old age - if only they would sell the land, the house in exchange for fake papers, airline tickets, or a consignment of goods that just fell off the truck.

This sense of preparedness, a readiness to switch gears, has significant implications for what residents think it is possible to do in the city. Households do display considerable determination and discipline, saving money over the course of several years to send children to school, build a house, or help family members 
migrate. They are in a place, and they demonstrate commitment to it. At the same time, African cities are a platform for people to engage with processes and territories that bear a marked sense of exteriority. The reference of this "exterior" has commonly been other cities, both within and outside the continent. Increasingly, it includes various interiors: rural areas, borders, and frontiers. These interiors may also be symbolic or spiritual and involve geographies that are off the map, as demonstrated in popular descriptions of subterranean cities, spirit worlds, or lucrative but remote frontiers. Cities straddle not only internal and external divides and national and regional boundaries but also a wide range of terrain and geography, both real and imaginary.

In many respects, then, Johannesburg not only displays and accelerates these tendencies by providing a rich urban infrastructure on which they operate, but it also stands as a receptacle, witness, and culmination of this preparedness. The inner city is a domain that few want to belong to or establish roots in. But it keeps alive residents' hopes for stability somewhere else, even as it cultivates within them a seemingly permanent restlessness and capacity to make something out of the city. One has to canvass only a small sample of the stories of foreign migrants to see how many different places they have been within the recent past. One informant from Cameroon showed me a passport with stamps from Congo, Angola, Namibia, Zimbabwe, South Africa, Dubai, India, Malaysia, Thailand, Singapore, China, Brazil, Uruguay, Paraguay, Chile, Peru, Venezuela, Guyana, Trinidad, and Argentina - all acquired over a seven-year period. The same holds true even for residents of South Africa, Lesotho, or Swaziland who may never have left the region but whose trajectories through diverse rural towns and urban townships encompass a very wide world.

Increasing numbers of Africans are situated in what could be called half-built environments: underdeveloped, overused, fragmented, and often makeshift urban infrastructures where essential services are erratic or costly and whose inefficiencies spread and urbanize disease. The majority of Africans still do not have access to clean water and sanitation. They are malnourished and, on average, live no longer than they did twenty years ago, even though the raison d'être of built environments would suggest a continuous trajectory toward the improved welfare of their inhabitants.

The international community has made a substantial effort over the last decade to help African municipalities direct urban growth and restructuring. Here, capacity building centers on developing proficient forms of codification. Not only does the city become the objective of a plurality of coding systems, it is meant to manifest itself more clearly as a system of codes. In other words, it is to be an 
arena where spaces, activities, populations, flows, and structures are made visible, or more precisely, recognizable and familiar.

Once this enhanced visibility is accomplished, urban spaces and activities are more capable of being retrieved and compared for analysis and planning. The emphasis is on the ability to locate and to define the built environment, specific populations, and activities so that they can be registered. The prevailing wisdom is that, once registered, these phenomena can be better administered and their specific energies, disciplines, and resources extracted. But it is clear that much of what takes place in African cities is fairly invisible: the number of people who reside in a given compound; how household incomes that can support only one week's survival out of every month are supplemented; or how electricity is provided for ten times as many households as there are official connections.

In Johannesburg's inner city, the heightened emphasis on visible identities and the converse need of actors to hide what they are actually doing generates a highly volatile mix. But it is in this play of the visible and invisible that limited resources can be put to work in many possible ways. Throughout urban Africa, residents experience new forms of solidarity through their participation in makeshift, ephemeral ways of being social. At the same time, these makeshift formations amplify the complexity of local terrain and social relationships by engaging the dynamics of a larger world within a coherent, if temporary, sense of place. Sometimes this sense of place coincides with a specific locality; other times, and with increasing frequency, it is dispersed across or in between discernible territories. In this economy of interpenetration, notions about what is possible and impossible are upended, and urban residents are ready to take up a variety of attitudes and positions.

Take, for example, African urban markets. They are renowned for being well run and for their multitude of goods and services overflowing whatever order is imposed upon them. In these markets, cooking, reciting, selling, loading and unloading, fighting, praying, relaxing, pounding, and buying happen side by side, on stages too cramped, too deteriorated, too clogged with waste, history, energy, and sweat to sustain all of them. Entering the market, what do potential customers make of all that is going on? Whom do they deal with and buy from? People have their networks, their channels, and their rules. But there are also wide spaces for most people to insert themselves as middlemen who might provide a fortuitous, even magical, reading of the market "between the lines," between stall after stall of onions or used clothes, between the fifty-cent profit of the woman selling Marlboros and five thousand freshly minted twenty-dollar bills stuffed 
into sisal bags with cassava and hair grease, tossed on top of a converted schoolbus heading somewhere into the interior. For it is these possibilities of interpretation, fixing, and navigation that enable customers to take away the most while appearing to deliver the minimum.

Throughout much of urban Africa, accidents, coercion, distinctly identified spaces, clandestine acts, and publicity are brought together in ways that trip up each of these categories. The clandestine becomes highly visible, while that which is seemingly so public disappears from view. More importantly, the apparently fragmented and disarticulated collection of quarters and spaces that make up the city are opened up to new reciprocal linkages.

These linkages are sometimes the constructions of individuals who desire to master self-limitations as opposed to merely straddling divides. At other times, urban residents invent a range of practices - religious, sexual, institutional capable of relocating individual actors within different frames of identity or recognition. This relocation enables them to understand their relationships with other actors and events in new, broader ways. Actors speak and deal with one another in ways that would otherwise be impossible. Such unanticipated interactions can be used to rehearse new ways of navigating complex urban relationships and to construct a sense of commonality that goes beyond parochial identities. Still, residents invest heavily in opportunities to become socially visible in ways that are not necessarily tied to formal associations. For example, throughout urban Africa, the proliferating neighborhood night markets do not simply provide an opportunity for localized trade or for extending trading hours, but serve primarily as occasions to be public, to watch others and whom they deal with, and to listen to their conversations. The task is to find ways to situate oneself so one can assess what is happening - who talks to whom, who is visiting whose house, who is riding in the same car, who is trading or doing business together-without drawing attention to oneself, without constituting a threat. ${ }^{14}$

Inner-city Johannesburg raises the stakes on these realities and capacities. It does not use the residual features of its "American side" to either resolve or make them more manageable, palatable, or visible. With its well-developed communications systems, efficient yet pliable banks, and relatively easy access to daily comforts, Johannesburg would appear to have more sophisticated parallel (though often illegal) economies than other African cities. What the inner city provides is

14. Asef Bayat, "Un-civil Society: The Politics of the 'Informal People,'” Third World Quarterly 18, no. 1 (1997): 53-72. 
an intersection where different styles, schemes, sectors, and practices can make something out of and from one another. In these respects, inner-city Johannesburg is the quintessential African city. Johannesburg becomes a launching pad not only for better livelihoods within the inner city but also for excursions into a broader world, whether Dubai and Mumbai or the pool halls of Hillbrow and the white suburb of Cresta only a few kilometers away. On the other hand, the density of skills, needs, aspirations, and willingness brought to work in the inner city makes it a sometimes brutal place, where everything seems to be on the line.

\section{Concluding Note}

The intensifying immiseration of African urban populations is real and alarming. For increasing numbers of urban Africans, their cities no longer offer them the prospect of improving their livelihoods or modern ways of life. Yet the theoretical reflections that underpin an ethnographic observation of inner-city Johannesburg point to how the growing distance between how urban Africans actually live and normative trajectories of urbanization and public life can constitute new fields of economic action. In striking ways, the translocal scope and multilateral transactions displayed by these more ephemeral economic machines are similar to the operations pursued by the dominant transnational economic networks of scale. But they are just similar, not the same-for their similarity is generated precisely through the disarticulation of coherent urban space. In significant ways, both the global/regional command centers and the dispersed, provisional, quotidian economies of the popular urban quarters do not intersect.

With limited institutional anchorage and financial capital, the majority of African urban residents have to make what they can out of their bare lives. Although they bring little to the table of prospective collaboration and participate in few of the mediating structures that deter or determine how individuals interact with others, this seemingly minimalist offering — bare life — is somehow redeemed. It is allowed innumerable possibilities of combination and interchange that preclude any definitive judgment of efficacy or impossibility. By throwing their intensifying particularisms - of identity, location, destination, and livelihoodinto the fray, urban residents generate a sense of unaccountable movement that might remain geographically circumscribed or travel great distances. 
AbdouMaliq Simone is assistant director of the Graduate Program in International Affairs at the New School University in New York and a visiting professor at the

Wits Institute for Social and Economic Research, University of the Witwatersrand. His books include In Whose Image: Political Islam and Urban Practices in the Sudan (1995) and For the City Yet to Come: Changing Urban Life in Africa (2004). 